\title{
0 microempreendedor individual (MEI) e o desenvolvimento territorial: uma análise da importância da legislação em diferentes escalas para efetivação da política pública
}

Elia Denise Hammes ${ }^{1}$ Rogério Leandro Lima da Silveira ${ }^{2}$

\section{Resumo}

O artigo objetiva demonstrar a importância da legislação relacionada à figura do microempreendedor individual (MEI), nas diferentes escalas, respeitadas suas competências constitucionais. A escala nacional se destaca pelos princípios constitucionais e pela regulamentação infraconstitucional da figura jurídica do microempreendedor individual, oportunizando o desenvolvimento territorial de forma isonômica em relação aos benefícios concedidos à figura do MEl. Compete às escalas nacional, estadual e local a elaboração de legislação que promova o tratamento jurídico diferenciado, visando ao incentivo e simplificação das obrigações administrativas, tributárias, previdenciárias e creditícias do microempreendedor individual, cada qual respeitando suas competências administrativas e legislativas. Na escala regional, a figura jurídica do MEI se destaca como instrumento de desenvolvimento regional diante da sua inserção no Plano Nacional de Desenvolvimento Regional (PNDR).

Palavras-chave: Microempreendedor individual. Legislação. Escalas. Desenvolvimento.

\section{Abstract}

This article aims to demonstrate the importance of the legislation related to the figure of the Single Micro-Entrepreneur - in different scales, respecting its constitutional powers. In a national scale it stands for its constitutional principles and the infra regulation of the legal figure concerning the Single Micro-entrepreneur, providing opportunities for the territorial development in an isonomic way where the benefits are granted to the Single Micro-entrepreneur figure. Even national, state and local extents are in charge of elaborating a legislation that promotes the differentiated legal treatment, seeking for encouragement and simplification of administrative obligations, social security and credit for the Single Micro-entrepreneur, each one respecting its administrative and legislative powers. For the regional extent the legal figure of the Single Micro-entrepreneur stands out as a regional development tool in view of their

\footnotetext{
${ }^{1}$ Mestre em Direito e doutoranda do Programa de Pós-Graduação em Desenvolvimento Regional da Universidade de Santa Cruz do Sul-UNISC. Professora de Direito Empresarial na mesma Instituição.elia@unisc.br

${ }^{2}$ Doutor em Geografia Humana. Professor do Programa de Pós-Graduação em Desenvolvimento Regional e do Departamento de História e Geografia - UNISC. rlls@unisc.br
} 
inclusion in the National Plan of Regional Development.

Keywords: Sigle Micro-Entepreneur. Legislation. Extent. Development.

\section{Introdução}

O projeto de desenvolvimento econômico pensado para o Brasil, especialmente a partir da Constituição Federal de 1988 (BRASIL, 1988), prevê, de forma inédita em relação às constituições anteriores, um favorecimento para as empresas de pequeno porte, que inclui os microempreendedores individuais (MEI). Além disso, as normas constitucionais estabelecem, no capítulo da ordem econômica, princípios de valorização do trabalho humano e garantia da livre iniciativa, assegurando a todos existência digna, conforme os ditames da justiça social. A legislação, nas escalas federal, estadual, distrital ${ }^{3}$ e local, é necessária para a instituição de políticas públicas, a fim de atender aos princípios constitucionais de um Estado de Direito, com o intuito de favorecer as empresas de pequeno porte.

Para fins jurídicos e econômicos, as empresas de pequeno porte são conceituadas, principalmente, a partir do seu enquadramento tributário. De acordo com a Lei Complementar no 123 de 2006 (BRASIL, 2006), atualmente é considerada como Empresa de Pequeno Porte (EPP) aquela que aufira, em cada ano-calendário, receita bruta superior a $\mathrm{R} \$ 360.000,00$ (trezentos e sessenta mil reais) e igual ou inferior a $\mathrm{R} \$ 3.600 .000,00$ (três milhões e seiscentos mil reais). Já no caso da microempresa (ME), é assim considerada aquela que aufira, em cada ano-calendário, receita bruta igual ou inferior a $\mathrm{R} \$ 360.000,00$ (trezentos e sessenta mil reais) ${ }^{4}$.

Como modalidade de microempresa (ME), recentemente (em 2008), foi instituído o microempreendedor individua I (MEI), objeto deste estudo, que, de acordo com a legislação, é considerado "o empresário individual a que se refere o Art. 966 o do Código Civil, que tenha auferido receita bruta, no ano-calendário anterior, de até $\mathrm{R} \$ 60.000,00$ (sessenta mil reais), optante pelo Simples Nacional".

Com o reconhecimento da figura do microempreendedor individual (MEI), pretendese retirar da informalidade inúmeras pessoas que realizam, individualmente ou com até um funcionário, negócios empresariais de pequeno porte sem qualquer registro. $\mathrm{O}$ intuito da Lei Complementar № 128 (BRASIL, 2008) é de que estes contribuam com os impostos, possam participar de licitações, componham as estatísticas do país e, principalmente, que os empreendedores tenham cobertura dos benefícios previdenciários concedidos aos empresários e funcionários das empresas formalizadas. A política pública é também uma forma eficaz de concretizar as normas constitucionais elaboradas pela constituinte de 1987/1988.

Com o objetivo de demonstrar a importância da legislação nas diferentes escalas para

\footnotetext{
${ }^{3} \mathrm{~A}$ legislação distrital se equaliza à estadual sobre o assunto.

${ }^{4}$ Para fins de formatação jurídica, essas empresas de pequeno porte podem se apresentar como sociedade empresária, empresa individual de responsabilidade limitada-EIRELI e o empresário individual, com empregados ou não.

${ }^{5}$ Dispõe o Art. 966: “Considera-se empresário quem exerce profissionalmente atividade econômica organizada para a produção ou a circulação de bens ou de serviços. Parágrafo único. Não se considera empresário quem exerce profissão intelectual, de natureza científica, literária ou artística, ainda com o concurso de auxiliares ou colaboradores, salvo se o exercício da profissão constituir elemento de empresa" (BRASIL, 2002).
} 
o sucesso da política pública instituída pela Lei Complementar no 128/2008, do microempreendedor individual (MEI), utilizaremos como referência o território nacional da República Federativa do Brasil, cujos entes federados possuem suas competências legislativas e administrativas estabelecidas pela Constituição Federal.

Porém, importante esclarecer que a legislação não é a única dimensão cuja referência à escala espacial de poder seja responsável pelo sucesso da política de inclusão do microempreendedor individual. De acordo com Vainer (2001, p. 147), “[...] qualquer projeto de transformação envolve, engaja e exige táticas em cada uma das escalas em que hoje se configuram os processos sociais, econômicos e políticos estratégicos". Nesse sentido, inúmeros arranjos e articulações, em diferentes escalas de poder ${ }^{6}$ que não apenas a divisão político-administrativa do país, são possíveis para o sucesso do negócio, porém aqui destacamos a legislação estatal.

Nesse sentido, a análise escalar, cada vez mais, vem adquirindo centralidade no campo das ciências sociais, e permeando diferentes posições, das quais destacamos aqui duas: a) a análise do desenvolvimento a partir da relação das escalas nacional $X$ internacional, o que se cristalizou a partir do período da I Guerra Mundial, e, mais recentemente, com a globalização em voga; e b) a relação das escalas local X global, que atualmente predominam nos estudos acadêmicos, sem enfatizar, no entanto, as escalas intermediárias, como a nacional e a regional (VAINER, 2001).

As narrativas escalares, que buscam compreender o fenômeno do desenvolvimento, têm papel fundamental para compreender também as relações entre Estado, economia e sociedade. A perspectiva escalar nacional versus a internacional não se justifica mais a partir da flexibilização do trabalho, da globalização do capital financeiro, de mercadorias e de prestações de serviços que não se restringem mais aos limites administrativos do Estado nacional.

De outro lado, em diferentes áreas do conhecimento, vem se dando ênfase à escala local, aqui compreendida como a do município, que se qualifica após a Constituição Federal de 1988 (BRASIL, 1988), com a autonomia concedida aos municípios, elevando-os a ente federado, uma peculiaridade do federalismo brasileiro. Promove-se sua independência em relação ao orçamento, consolida-se o autogoverno, com a eleição de prefeitos, vereadores, e legislação própria em relação aos assuntos de interesse local, inclusive fiscal, (Art. 29 e 30 da CF/88), além de competências legislativas e administrativas próprias, conforme Art. 22 e 23 da CF/88.

O município como ente federado é considerado pela teoria localista como ente capaz de se articular com o global sem a interferência das escalas intermediárias - nacional, estadual e regional -, permitindo, por exemplo, que os governos municipais negociem a vinda de empresas globais para o seu território, subsidiando-as com isenções de toda ordem, com o intuito de gerar emprego, renda e promover o desenvolvimento territorial, o que nem sempre se realiza no plano empírico da realidade brasileira.

A corrente que enfatiza a relação escala global $X$ local defende que os governos locais teriam "mais eficazmente que qualquer outra instituição ou nível escalar, [...] condições de: a) atrair e promover a competividade das empresas; b) oferecer base histórica e cultural para a integração dos indivíduos" (VAINER, 2001, p. 142). Ainda, para a corrente localista, "o governo local teria extraordinária capacidade de cumprir de maneira vantajosa as tradicionais funções que sempre foram as dos estados nacionais, quais sejam: a função de acumulação e a função

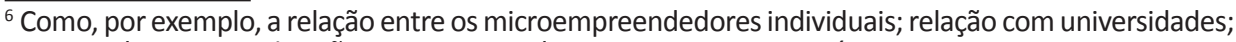
os acordos com instituições e empresas de maior porte; os consórcios, etc.
} 
de legitimação" (VAINER, 2001, p. 142).

Em relação à figura do microempreendedor individual, a escala local, como veremos, perde força diante do cabedal legislativo que instituiu a política pública do microempreendedor individual, ao compartilhar com os demais entes federados, nas demais escalas espaciais, a responsabilidade de viabilizar a política nacional.

Crítico das teorias localistas, Brandão (2007) aponta que as posições que tratam do potencial "exagerado" dos locais, que se pauta pela ideia de "vender a região ou a cidade", com busca desenfreada de atividades a novos investimentos, melhorando o "clima local dos negócios", subsidiando os custos tributários, fundiários e salariais dos empreendimentos, compromete, muitas vezes em longo prazo, as finanças locais pela guerra entre os locais em busca de grandes empresas multinacionais, como exemplifica (BRANDÃO, 2007, p. 39).

Para Brandão (2007, p. 6), “[...] nenhuma escala per se é boa ou ruim. [...] é preciso discutir a espacialidade dos problemas e implementar políticas levando em consideração a escala específica desses problemas, mas em um contexto em que esteja presente um projeto nacional de desenvolvimento", como é o caso da política de desenvolvimento do Brasil que inclui as microempresas.

Desenvolvemos a análise a partir do arcabouço legislativo possível das diferentes escalas sobre o território, a fim de viabilizar a política pública do MEI. Inegavelmente, haverá maior facilidade na análise de algumas escalas relacionadas ao MEI do que em outras, mas esse é um processo a ser enfrentado, e, como afirma Brandão (2007, p. 6), “[...] selecionar analiticamente a escala mais conveniente dos problemas observados faculta melhor diagnosticá-los e possibilita sugerir coalizões de poder e decisões estratégicas sobre como enfrentá-los". Nessa mesma linha de pensamento nos alinhamos a Brandão, quando afirma que "o desafio (simultaneamente) científico e político é, portanto, procurar definir o que e com que meios cada escala pode revelar, mobilizar, contestar, acionar, regular, comandar e controlar" (BRANDÃO, 2007, p. 6).

O artigo objetiva demonstrar a importância da legislação de cada ente federado, respeitadas suas competências constitucionais, instituindo políticas públicas e de ações estatais de diferentes escalas, que se relacionam com a figura do microempreendedor individual.

Nesse sentido, e com base nesse referencial teórico, organizamos nossa reflexão em quatro momentos. Inicialmente, analisamos a legislação relacionada à figura do microempreendedor individual na escala nacional, com destaque à Constituição Federal, que estabelece princípios constitucionais que norteiam as políticas públicas no Brasil, especialmente aquelas relacionadas às pequenas empresas. Num segundo momento, abordamos as possíveis e diferentes legislações que favorecem os pequenos empreendimentos na escala dos Estados, partindo da atribuição de competência estabelecida pela Lei Maior, nos termos do Art. 179, e ilustrando com iniciativas legislativas do Estado do Rio Grande do Sul7. Na sequência, abordamos a proposta legislativa da segunda Política Nacional de Desenvolvimento Regional (PNDR), que inclui a figura do microempreendedor como instrumento de desenvolvimento regional. Por fim, num último tópico, analisamos a importância da legislação na escala local, em prol do microempreendedor individual para o desenvolvimento territorial.

\footnotetext{
${ }^{7}$ Optamos pela legislação do Estado do Rio Grande do Sul pela sua familiaridade com os pesquisadores, em decorrência de outras pesquisas realizadas.
} 


\section{0 protagonismo da escala nacional em relação à política do microempreendedor individual (MEI)}

A concretização dos princípios constitucionais, e aqui em destaque aquele que garante favorecimento para as empresas de pequeno porte, vem sendo realizada, especialmente por leis elaboradas no âmbito nacional, pela figura jurídica da União, que, sem dúvida, é a maior protagonista dessa política pública, convergindo para a posição de Vainer, quando este afirma que "[...] é o Estado Nacional, única escala e instituição escalar em condições de viabilizar, suscitar, a construção de alternativas viáveis ao capitalismo simultaneamente globalitário e fragmentador" (VAINER, 2001, p. 145).

Com intuito de estabelecer um marco na concretização do tratamento favorável às pequenas empresas no Brasil, destacamos a norma constitucional promulgada em 5 de outubro de 1988, que, como já foi mencionado, favorece as empresas de pequeno porte constituídas sob as leis brasileiras e que tenham a sede de sua administração no Brasil, nos termos do Art. 170, IX da Lei Maior.

Destacamos também a Lei no 9.317, de 5 de dezembro de 1996, que dispõe sobre o regime tributário das microempresas e das empresas de pequeno porte, instituindo o sistema integrado de pagamento de impostos e contribuições para as microempresas, denominado de "Lei do Simples", importante medida aplicada a todo o território nacional, que simplificou e reduziu a carga tributária das pequenas empresas.

Há, ainda, a Lei Complementar no 123, de 14 de dezembro de 2006 (BRASIL, 2006), que institui o Estatuto Nacional da Microempresa e da Empresa de Pequeno Porte, e revoga a Lei no 9.317/1996. A referida lei vem sofrendo, por meio de outras leis complementares, significativas modificações, a fim de adequar-se à dinâmica empresarial e assegurar o princípio constitucional norteador das pequenas empresas, incentivando a formalização das pequenas atividades econômicas. Essa lei sofreu significativa alteração pela Lei Complementar no 128, de 19 de dezembro de 2008, que institui no Estatuto Nacional da Microempresa e da Empresa de Pequeno Porte a figura do Microempreendedor Individual (MEI), como será daqui em diante identificado.

Recentemente, foi promulgada a Lei Complementar no 147, de 7 de agosto de 2014, alargando os benefícios concedidos às micro e pequenas empresas, com o intuito de, efetivamente, concretizar os princípios da ordem econômica estabelecidos pela Constituição Federal. A respectiva lei permite, inclusive, uma melhor compreensão do instituto do MEl. Esclarece a nova legislação, em seu Art. 18 e seus parágrafos, que o "MEl é uma modalidade de microempresa", e que "[...] o instituto do MEl é uma política pública que tem por objetivo a formalização de pequenos empreendimentos e a inclusão social e previdenciária". Estabelece ainda que "a formalização de MEI não tem caráter eminentemente econômico ou fiscal", permitindo concluir que a respectiva política pública é uma política econômica, mas também social, estabelecida em nível nacional, dada sua importância inclusiva, alargando a lista de atividades que podem se formalizar por meio do instituto do MEl. ${ }^{8}$

\footnotetext{
${ }^{8}$ Atividades de comércio e indústria já estavam contempladas para se constituir em forma de $\mathrm{MEI}$, desde que atendidas às exigências de limite de faturamento e outras, já as atividades de prestação de serviços eram limitadas para se formalizar por meio do $\mathrm{MEI}$, o que foi modificado pela Lei Complementar no 147/2014.
} 
O entendimento de que o MEl é uma política inclusiva viabiliza não só a concretização dos princípios constitucionais elencados como fundamentos do Estado brasileiro, como a dignidade da pessoa humana, mas também dos princípios da ordem econômica de valorização do trabalho humano, da livre iniciativa, entre outros, bem como demais políticas inclusivas adotadas pelo Estado brasileiro nos últimos anos. ${ }^{9} \mathrm{O}$ papel inclusivo de tal política repercute também na compreensão das escalas, deixando claro que não se trata de um instituto com forte conteúdo arrecadatório, ou seja, que não favorecerá a arrecadação dos cofres públicos mediante sua característica de política extrafiscal, o que pode ser exemplificado com a contribuição previdenciária do $\mathrm{MEI}$, que representa $5 \%$ sobre o salário mínimo e que confere ao empreendedor e a sua família o direito de cobertura previdenciária, como auxílio-doença, aposentadoria por idade, salário-maternidade, após carência, pensão e auxílio reclusão.

Para fortalecer a proposta de política econômica e social, na medida em que propõe também a inclusão social, outras medidas, na escala nacional, somam-se à criação da figura do MEl.

O fortalecimento político nacional da categoria dos pequenos empreendedores é fator relevante na concretização da norma constitucional. Recentemente, foi criada a Secretaria das Micro e Pequenas Empresas, por meio da Lei no 12.792, de 28 de março de 2013 (BRASIL, 2013). Essa Secretaria, apesar de não mencionar expressamente políticas públicas que possam ser aplicadas ao $\mathrm{MEl}$, assegura políticas a serem implementadas em todas as empresas que se caracterizam como micro e pequenas, incluindo os MEls, que, como já foi mencionado, também é uma modalidade da microempresa. Além dessas medidas na esfera nacional, cabe mencionar ainda a Lei no 11.110, de 25 de abril de 2005 (BRASIL, 2005), que institui o Programa Nacional de Microcrédito Produtivo Orientado. Segundo a própria lei, "considera-se microcrédito produtivo orientado o crédito concedido para o atendimento das necessidades financeiras de pessoas físicas e jurídicas empreendedoras de atividades produtivas de pequeno porte".

Observa-se que a escala nacional é fundamental na efetivação da política pública aqui analisada, pois padroniza para todo o território nacional a oportunidade de formalização das políticas, mas, por outro lado, a contribuição das demais escalas, de acordo com suas competências, é fundamental para a efetivação da política.

\section{As competências residuais dos Estados para efetivação da política pública do microempreendedor individual}

Em nível estadual, o ponto de partida também se dá a partir do texto constitucional em vigor, que reservou aos Estados federados competências exclusivas, legislativas e administrativas residuais; de acordo com o §1으 do Art. 25 da Lei Maior, "São reservadas aos Estados as competências que não lhes sejam vedadas por esta Constituição" ${ }^{10}$, ou seja, cabe ao Estado

9 São exemplos de políticas inclusivas o Bolsa Família, o Programa Minha Casa Minha Vida, Quotas Sociais, entre outros.

${ }^{10}$ As únicas competências exclusivas que a CF/88 estabelece aos estados federados são de exploração de gás canalizado e da criação de regiões metropolitanas, aglomerações urbanas e microrregiões, constituídas por agrupamentos de municípios limítrofes, nos termos do Art. 25 do texto constitucional. 
tudo o que não é de competência da União e dos municípios - competência residual. Nesse sentido, ao serem analisadas as competências da União e dos municípios, pouco resta aos estados federados. De acordo com Mendes, Branco e Coelho (2007):

A competência residual do Estado abrange matérias orçamentárias, criação, extinção e fixação de cargos públicos estaduais, autorização para alienação de imóveis, criação e secretariais de Estado, organização administrativa, judiciaria e do Ministérios Público, da defensoria Pública e da Procuradoria-Geral do Estado.

Todas as demais competências atribuídas aos estados federados são competências comuns entre todos os entes federados, como pode ser notado no Art. 23, quando estabelece que é de competência comum da União, dos Estados, do Distrito Federal e dos Municípios, o combate "[...] às causas da pobreza e dos fatores de marginalização, promovendo a integração social dos setores desfavorecidos", além de estabelecer "[...] normas para a cooperação entre a União e os Estados, o Distrito Federal e os Municípios, tendo em vista o equilíbrio do desenvolvimento e do bem-estar em âmbito nacional". Na esfera econômica, o Art. 179, do mesmo texto constitucional, estabelece importante competência comum entre os entes federados:

A União, os Estados, o Distrito Federal e os Municípios dispensarão às microempresas e às empresas de pequeno porte, assim definidas em lei, tratamento jurídico diferenciado, visando a incentivá-las pela simplificação de suas obrigações administrativas, tributárias, previdenciárias e creditícias, ou pela eliminação ou redução destas por meio de lei (grifo nosso).

Nesse sentido, o Estado do Rio Grande do Sul constituiu a Secretaria da Economia Solidária e Apoio à Micro e Pequena Empresa (SESAMPE), que surgiu com a reforma administrativa promovida pelo Governador Tarso Genro (2010-2014) no início de sua administração. Foi criada pela Lei no 13.601, de 1ㅇ de janeiro de $2011^{11}$ (RIO GRANDE DO SUL, 2011). Por meio dessa Secretaria, houve a implantação do Programa Redes de Cooperação, cujo objetivo é reunir empresas com interesses comuns em Redes de Cooperação, constituindo uma entidade juridicamente estabelecida, sem quotas de capital, que mantém a independência legal e a individualidade de cada empreendimento participante, conforme estabelece a página oficial do governo (RIO GRANDE DO SUL, 2015)

Outra medida que pode ser tomada na escala estadual é a implementação da po-

\footnotetext{
${ }^{11}$ Art. 36 - Compete à Secretaria da Economia Solidária e Apoio à Micro e Pequena Empresa: I - promover e difundir os conceitos de associativismo, solidariedade, autogestão, desenvolvimento sustentável e de valorização das pessoas e do trabalho; ll - proporcionar a criação e a manutenção de oportunidade de trabalho e a geração e distribuição de renda; III - estimular a produção e o consumo de bens e serviços oferecidos pelo setor da Economia Popular Solidária; IV - promover, incentivar e ampliar a competitividade das micro e pequenas empresas, inclusive por meio de investimento comercial, industrial e de serviços; $V$ - apoiar e promover projetos que estimulem a geração de trabalho e renda com foco na economia solidária; VI - executar o registro de empresas; VII - apoiar o empreendedorismo e a competitividade de micro e pequenas empresas; VIII - apoiar o desenvolvimento de projetos microempresariais na área de gestão e de tecnologia da informação; IX - gerir fundos de desenvolvimento na sua área de competência; $X$ - promover a formação, a educação e a capacitação técnica para cooperação e autogestão; XI - promover a incubação e a assistência técnica para implementação de empreendimentos da economia solidária; XII - apoiar técnica e financeiramente a recuperação e a reativação de empresas por trabalhadores; XIII - fomentar a comercialização de produtos e serviços; XIV - implementar a Política Estadual de Fomento à Economia Popular Solidária e dar suporte administrativo ao Conselho do setor.
} 
lítica de microcrédito, estabelecendo benefícios e facilidades aos microempreendedores individuais. A título ilustrativo, no Estado do Rio Grande do Sul, pode-se citar o Decreto no 48.164, de 15 de Julho de 2011, que objetiva fortalecer e ampliar o microcrédito no âmbito do Estado em parceria com Instituições Financeiras, Agentes de Intermediação e Instituições de Microcrédito, na intermediação de recursos e operacionalização de uma variedade de empréstimos direcionados a um público restrito, contemplando empreendedores formais e informais, pessoas físicas e jurídicas, definidos por sua baixa renda ou pelo seu ramo de negócios, que usualmente não têm acesso às formas convencionais de crédito em que se enquadram os microempreendedores individuais.

Essas não são as únicas políticas estaduais que beneficiam o $\mathrm{MEI}$, porém nos restringiremos a elas pela limitação do presente trabalho.

Mas, como se pode perceber, a política na escala nacional é determinante para a instituição da figura do $\mathrm{MEI}$, cabendo aos estados federados, assim como aos municípios, como veremos adiante, impulsionar, facilitar a vida dos pequenos empreendedores, aprimorando o favorecimento de tratamento estabelecido na Constituição Federal e regulamentado pelas leis federais.

\section{$4 \mathrm{O} \mathrm{MEI}$ como instrumento jurídico de desenvolvimento regional}

A espacialidade regional vem se estabelecendo, cada vez mais, como importante escala a ser considerada para fins de desenvolvimento territorial. Segundo Cargnin (2014, p. 74), "há, entre os governos estaduais e municipais, uma lacuna político-administrativa que tem dificultado a propagação de uma cultura alicerçada na construção de estratégias regionais e de projetos que envolvam soluções para fora dos limites municipais", predominando as questões que são objeto direto das representações municipais, não havendo um processo mais amplo que extrapole os limites administrativos dos municípios e dos estados ${ }^{12}$.

Atentando para essa questão, e com o intuito de estabelecer uma organização que oriente, de forma estratégica, convergente e eficiente, as ações de investimentos públicos, voltados ao desenvolvimento integrado do Território Nacional, conforme preceitua a Constituição Federal (Art. 1ํ), institui-se a Política Nacional de Desenvolvimento Regional (PNDR). Embora esta não seja a única política que atenda às necessidades e peculiaridades de cada região, elegemos, para fins deste estudo, a proposta legislativa da II PNDR como política - de Estado - de desenvolvimento regional, que contempla, como veremos adiante, a figura do $\mathrm{MEI}$ como instrumento de desenvolvimento regional, o que não impede a adoção de outras políticas, as quais atentam à escala regional, diante das particularidades de cada região.

Questão importante a ser considerada é a de que a II PNDR, assim como a primeira ${ }^{13}$, é uma proposta de lei federal que tem como foco determinadas regiões, as quais foram

${ }_{12}$ Considerando aqui região em um sentido amplo, podendo representar vários municípios, inclusive de diferentes Estados, bem como áreas territoriais de diferentes Estados do Brasil.

${ }^{13}$ A primeira PNDR foi instituída em 22 de fevereiro de 2007, por meio do Decreto no 6.047. Já a segunda PNDR está em fase de proposta, prestes a ser enviada ao Congresso Nacional. 
${ }^{14} \mathrm{~A}$ atual redação da proposta legislativa para a segunda PNDR assim dispõe sobre as áreas de atuação: Art. 60. A PNDR possui abrangência nacional com atuação em múltiplas escalas geográficas.

Art. 70. O critério para a definição de Regiões Elegíveis da PNDR é o nível de desenvolvimento das microrregiões do Instituto Brasileiro de Geografia e Estatística - IBGE, que são classificadas e vinculadas aos objetivos específicos descritos no Art. 2 ㅇ.

Art. 8‥ Em relação ao Objetivo I, são elegíveis as microrregiões - MRGs cujo Rendimento Domiciliar Per Capita - RDPc médio se encontra abaixo de $75 \%$ do RDPc médio do País.

Parágrafo Único. As prioridades de atuação nessa classificação são definidas pelo indicador de dinamismo econômico, medido pela Variação do Produto Interno Bruto - PIB na MRG considerado em relação à mediana da variação do PIB nacional, sendo: I - Prioridade I: Espaços com RDPc abaixo de $50 \%$ da média nacional e entre $50 \%$ e $75 \%$ da média, de baixo dinamismo, sendo a variação do PIB menor que mediana da variação do PIB nacional; II - Prioridade II: Espaços com RDPc entre $50 \%$ e 75\% da média nacional e com alto dinamismo, sendo a variação do PIB maior que a mediana da variação do PIB nacional.

Art. 9‥ Em relação ao Objetivo II, são elegíveis as MRGs que apresentaram crescimento populacional negativo e aquelas que cresceram a taxas inferiores a $50 \%$ da média nacional, medidos pela Taxa de Crescimento Populacional da MRG em relação à média nacional do último Censo Demográfico do IBGE.

Art. 10․ Em relação ao Objetivo III, são elegíveis as MRGs que apresentam elevado percentual de participação de commodities agrícolas e minerais em sua produção total ou em suas exportações.

Parágrafo Único. O Ministro de Estado da Integração Nacional publicará Portaria Ministerial definindo as MRGs elegíveis para este objetivo.

Art. 11. Em relação ao Objetivo IV, será publicada Portaria Interministerial dos Ministros de Estado da Integração Nacional, das Cidades e do Planejamento Orçamento e Gestão, definindo a Rede de Cidades-Polo prioritária.

$\S 10$ Estudo técnico será realizado para subsidiar a definição da Rede de Cidades-Polo prioritária, devendo:

I - Considerar a caracterização e propostas da pesquisa Regiões de Influência de Cidades, do IBGE, e do estudo Dimensão Territorial para o Planejamento, do Ministério do Planejamento, Orçamento e Gestão - MPOG, e atualizações;

II - Incluir consulta a especialistas, formuladores de políticas, agentes públicos e lideranças regionais e locais;

III - Tratar a Rede de Cidades-Polo em múltiplas escalas geográficas;

IV - Dar tratamento diferenciado às Redes de Cidades do Semiárido Brasileiro, da Amazônia Legal e da Faixa de Fronteira.

$\S 2$ o Será elaborado o Plano de Desenvlvimento da Rede de Cidades com definição de metas concretas de fortalecimento dos polos, especialmente no que se refere à infraestrutura logística, à rede de banda larga e à oferta de serviços básicos, que ampliem sua capacidade em termos de polarização, comando e organização do território.

Art. 12. São Regiões Especiais Prioritárias da PNDR o Semiárido Brasileiro, a Faixa de Fronteira e a Região Integrada de Desenvolvimento do Entorno do Distrito Federal.

Art. 13. As microrregiões enquadradas em um ou mais critérios de elegibilidade descritos, as macrorregiões onde mais de $70 \%$ de suas microrregiões se enquadrem nos critérios do Objetivo I, assim como as Regiões Especiais Prioritárias constituem as Regiões Elegíveis da PNDR.

Art. 14. Regiões Programa poderão ser criadas, a qualquer tempo e em diferentes escalas geográficas, a partir de proposta de qualquer das instâncias de governança do SGDR.

$\S 1$. . As Regiões Programa serão criadas por tempo determinado e deverão:

I-Ser compostas por Regiões Elegíveis da Política, considerando que regiões não elegíveis poderão ser integradas se forem parte das estratégias definidas;

II - Criar, articular ou integrar instância de governança participativa responsável pela elaboração de PDRS, em conformidade com o Art. 40;

III - Considerar os instrumentos de planejamento descritos no Título III;

$\S 2$ ㅇ São também consideradas Regiões Programa as regiões Xingu, Entorno da BR 163, Ilha do Marajó, que são objeto de Planos de Desenvolvimento Regional ativos.

$\S 300$ entorno de grandes projetos de infraestrutura, de grandes projetos produtivos financiados com recursos de bancos públicos de desenvolvimento e as regiões imediatas de influência dos municípios polo que forem priorizados como novas centralidades da Rede Policêntrica deverão se constituir necessariamente em Regiões Programa.

Art. 15. A tipologia da PNDR será revista e atualizada a cada censo demográfico do IBGE.

Art. 16. A classificação das diversas microrregiões a partir dos critérios de elegibilidade não autoriza a implementação de ações padronizadas, devendo-se considerar as especificidades regionais e o envolvimento dos atores locais. 
Para atender às mazelas das regiões eleitas pela proposta legislativa da II PNDR, as políticas públicas podem pretender altos investimentos bem como o fomento e incentivo da formalização de atividades desenvolvidas por pequenos empreendedores, o que pode ser feito por meio da figura jurídica do MEl. Além das áreas eleitas a priori, outras podem ser inclusas por meio da criação de Regiões Programa.

A figura jurídica do MEl está contemplada expressamente como instrumento para o desenvolvimento. As áreas eleitas apresentam um nível de desenvolvimento abaixo da média nacional, e a formalização das atividades econômicas, ainda que de pequeno porte, é importante questão a ser atacada, visto que o PIB computado, especialmente nas regiões eletivas da segunda PNDR, não considera as atividades informais, mas apenas as receitas declaradas de atividades formais.

Dessa forma, a figura do MEI é contemplada, de forma expressa, no eixo ciência e tecnologia, no qual destacamos a diretriz de "[...] estruturar e/ou fortalecer Redes Estaduais de Extensão Tecnológica como foco em micro ${ }^{15}$, pequenas e médias empresas, fortalecendo as redes de extensão existentes, quer no âmbito federal, como o Sistema Brasileiro de Tecnologia (Sibratec), quer no âmbito estadual, por meio das fundações de amparo à pesquisa (FAPs)".

Já no eixo do desenvolvimento produtivo, o MEI está contemplado em mais de uma diretriz, conforme se pode observar:

Estabelecer mecanismos para fortalecer as pequenas e microempresas, microempreendedores individuais, cooperativas, associações, pequenos produtores rurais e a agricultura familiar, por meio do fomento, da inclusão produtiva e do acesso ao conhecimento e à assistência técnica. Definir estruturas e critérios especiais para análise, concessão e prestação de contas de financiamentos destinados às micro e pequenas empresas, microempreendedores individuais, cooperativas, associações, produtores rurais e agricultores familiares, bem como apoio a projetos de cadeias produtivas e APLs, isentando-os de taxas municipais, estaduais e federais, no primeiro ano de funcionamento, retirando os impostos inclusos na energia elétrica, criando ações de mitigação de risco de crédito, estabelecendo diferenciais nas condições de crédito, beneficiando empreendimentos inovadores, comprometidos com práticas sustentáveis e ou de exploração do potencial da biodiversidade das regiões, disponibilizando fundos específicos para o fomento ao empreendedor individual e às micro, pequenas e médias empresas (grifo nosso).

Considerando que a escala regional é órfã de um poder legiferante, e que determinada região pode ultrapassar as linhas administrativas dos Estados federados, a política da escala nacional do MEl impõe ainda mais a sua importância. Além do que, na medida em que uma região pode abranger diferentes Estados e diferentes municípios, a escala regional não concentrará todas as necessidades para o desenvolvimento da política desenvolvimentista do pequeno empreendedor. A escala regional necessita das demais escalas, pois o sistema em que se enquadra está dentro de uma perspectiva local, regional, estadual, nacional, global (BRANDÃO, 2007).

${ }^{15}$ Considerando que o MEl é uma modalidade de microempresa. 


\section{A legislação na escala local em prol do microempreendedor individual (MEI)}

Iniciamos identificando, para fins deste trabalho, escala local como o município e, para tanto, destacamos a importância dessa escala articulada com as demais para o desenvolvimento das atividades econômicas empresárias passíveis de serem formalizadas e enquadradas como MEl.

O já citado Art. 179 da Constituição Federal estabelece a importância da escala local, que determina que caberá tanto à União quanto aos Estados, Distrito Federal, bem como aos Municípios (grifo nosso) dispensar às microempresas e às empresas de pequeno porte tratamento jurídico diferenciado, visando incentivar a simplificação das obrigações administrativas, tributárias, previdenciárias e creditícias, ou, então, eliminá -las ou reduzi-las, por meio de lei a ser aprovada nas instâncias da competência de cada ente federado.

Dada a importância de os municípios regulamentarem a figura do $\mathrm{MEI}$, com a simplificação de suas obrigações administrativas, tributárias, previdenciárias e creditícias, cabe, na escala local, verticalizar e concretizar o que é de competência do município: o tratamento favorecido às pequenas empresas.

Exemplos de pontos específicos que podem ser regulados por lei municipal em prol do microempreendedor individual são os incentivos fiscais, o apoio à inovação tecnológica, o associativismo, por meio da constituição de sociedade de propósito específico entre MEls, a política de incentivo à formalização dos pequenos empreendimentos, a organização de feiras locais, além do incentivo à participação dos microempreendedores individuais em eventos nacionais e internacionais, facilitações para encaminhamento de alvarás, entre outros benefícios que podem ser instituídos na escala local.

A lei local pode ainda regulamentar o acesso aos mercados, por meio da participação facilitada às licitações do município, bem como estimular o crédito e a capitalização dos MEls, por meio de fatia do seu orçamento, reservada para apoiar as atividades econômicas exercidas pelo MEI.

Ademais, as leis locais terão que se adaptar à recente Lei Complementar no 147, de 2014, que estabelece que a tributação municipal do imposto sobre imóveis prediais urbanos (IPTU), que é um imposto de competência exclusiva dos municípios instituir e cobrar, deve assegurar tratamento mais favorável ao $\mathrm{MEI}$, para a realização de sua atividade no "[...] mesmo local em que residir, mediante aplicação da menor alíquota vigente para aquela localidade, seja residencial ou comercial, nos termos da lei, sem prejuízo de eventual isenção ou imunidade existente"(Art. 18-D). Tal regulamentação se justifica na medida em que pesquisa realizada pelo SEBRAE (2015), com dados colhidos até abril de 2012, aponta:

Do total de $\mathrm{MEI}$, os números mostram que $43 \%$ atuam em seu próprio domicílio, $34 \%$ em estabelecimento comercial, $12 \%$ na rua e $11 \%$ no domicílio ou empresa do cliente. Somando-se os que afirmam atuar em seu domicílio ou em estabelecimento comercial, tem-se que $77 \%$ dos microempreendedores individuais atuam em ponto fixo.

A Lei Complementar no 128, de 19 de dezembro de 2008, que institui a figura do $\mathrm{MEI}$, de acordo com o Art. 14, inciso III, estabeleceu vacatio legis para a respectiva lei 
em relação ao MEI, produzindo efeito a partir de 10 de julho de 2009, permitindo, assim, que as escalas estadual e local constituíssem, ou adequassem suas legislações, a fim de garantir tratamento favorecido não só às pequenas empresas em geral mas também à figura do MEl.

A imposição de criação de lei no âmbito local não vem sendo observada por todos os municípios. Notícias, como a publicada por Luiz Gonzaga de Lima de Morais, na Revista da Semana, de 15 de agosto de 2010, intitulada "TCE e MP alertam prefeitos para aprovarem lei do empreendedor individual", dão conta de que de muitos municípios até o presente momento sequer instituíram o MEI por lei municipal, por motivos diversos, os quais podem ter relação com a falta de compreensão e repulsa à política de inclusão que se pretende com a instituição da figura jurídica do $\mathrm{MEI}$, até outros motivos que merecem ser investigados.

Por fim, com o cenário do aparato legislativo que atinge o microempreendedor individual, cabe ainda destacar Cargnin (2014), quando assinala que, com a Constituição Federal como marco importante, somada a estabilização econômica "[...] e o arrefecimento da onda privatista, no final dos anos de 1990, começaram a aparecer os primeiros sinais de uma efetiva recuperação do planejamento de médio e longo prazo entre as atividades e planos de desenvolvimento elaborados pelos Estados" (CARGNIN, 2014, p. 63).

Destaca-se também que o planejamento territorial voltado à inclusão dos pequenos empreendedores, por meio da figura jurídica do microempreendedor individual foi incorporado "[...] à escala nacional através da ação do Governo Federal, que passou a dar maior ênfase à elaboração de estratégias de futuro, integração territorial e redução de desigualdades regionais" (CARGNIN, 2014, p. 63).

No entanto, Brandão (2007) argumenta que a escala local é detentora de forte potencial, devido às suas particularidades políticas, sociais, econômicas e culturais, mas as ações nesta escala são altamente dependentes de outras, desenvolvidas nas escalas tanto regionais e estaduais, quanto nacionais e também globais. Na medida em que é na escala nacional que se estabelece a política pública de tratamento favorecido aos pequenos empreendedores e se institui a figura jurídica do microempreendedor individual para essa finalidade, torna-se imprescindível a articulação de ações em todas as escalas na medida de suas competências legislativas.

$\mathrm{E}$, por fim, ainda que o estudo tenha se restringido ao território da divisão administrativa do país, não se pode ignorar as interferências da escala global na condução da política aqui destacada.

Assim, as ações planejadas para esse território precisarão ter uma articulação entre todas as escalas (local, regional, estadual e nacional). Para Brandão (2007), quanto maior o número de escalas entre o local e o global, tanto maior será a capacidade de se criar mecanismos de resistência à escala global, de modo que, quando se reduzem as escalas a uma análise local e global, a segunda tende a dominar a primeira, pois sua estrutura e capacidade em relação à detenção do capital (poder) é infinitamente maior que a da escala local (BRANDÃO, 2007), motivo pelo qual se torna importante a existência de legislação em todas as escalas, estabelecendo lastro à manutenção do microempreendedor mesmo diante de crises internacionais. 


\section{Considerações finais}

Ao considerar trabalho informal como o conjunto de trabalhadores que não contribuem com a previdência social, a figura do microempreendedor individual, instituída a partir da Lei Complementar no 128, de 2008, serve como uma nova forma de regularizar o trabalho informal, uma vez que a figura do MEl permite a formalização de negócios com baixo custo bem como sua manutenção com redução da carga tributária, próprio de uma política inclusiva, conforme menciona expressamente a Lei Complementar de no 147 de 2014.

A legislação que dá lastro à política pública do MEl é imprescindível para a sua efetivação, preconizando, inclusive, o Estado de Direito estabelecido na lei maior do país. A formalização e funcionamento de empresas, inclusive as do $\mathrm{MEI}$, respeita legislações de diferentes escalas. As medidas necessárias para que o MEI funcione como política inclusiva, como se viu, depende de ações legislativas das diferentes escalas que representam os entes federados do país.

A escala nacional é protagonista dessa política pública, na medida em que padroniza as mesmas possibilidades de desenvolvimento territorial, por meio da formalização das atividades informais em todo o território brasileiro, permitindo, inclusive, a concretização dos mais variados princípios constitucionais inicialmente destacados. A importância da escala nacional se evidencia também pela possibilidade de coordenação de medidas administrativas e tributárias isonômicas nas demais escalas do território, impondo até mesmo medidas a serem tomadas pelas demais escalas, a fim de viabilizar a atividade econômica formal do MEI, como, por exemplo, com a imposição de aplicação da menor alíquota vigente no município, para a cobrança do IPTU do imóvel em que o MEl está estabelecido, com a possibilidade de aproveitar eventual isenção ou imunidade anterior à formalização existente para o imóvel.

Já a escala estadual, que se caracteriza pelas competências residuais, possui amplo espaço para o fomento das atividades desenvolvida por MEls. As ações legislativas da escala estadual dependem da exata compreensão por parte dos governantes de que o MEI não é um empresário com potencial arrecadatório a favor do Estado, mas que pode representar maciçamente o autoemprego, permitindo benefícios, especialmente previdenciários, antes não acessíveis ao empreendedor informal, e, com isso, destinando parte do orçamento do Estado ao fomento do $\mathrm{MEI}$, como é o caso do microcrédito.

Recentemente, a figura jurídica do MEI foi incorporada ao texto legislativo do segundo Plano Nacional de Desenvolvimento Regional (PNDR), que pretende constituir uma lei ordinária federal, com propósito específico de desenvolver regiões pré-eleitas

e outras que podem exigir um olhar mais atento da ação estatal. A escala regional não possui autonomia legislativa, potencializando as ações legislativas das escalas nacional, estadual e municipal, diante da realidade de que as regiões podem envolver territórios geográficos que pertencem a diferentes organizações político-administrativas do território brasileiro.

A escala local se destaca porque a atividade econômica do MEI se materializa no âmbito local, atribuindo, em tese, maior responsabilidade a essa escala. No âmbito da escala local, é fundamental a existência de legislação concedendo tratamento favorecido 
à pequena empresa e ao MEI diante das competências legislativas e administrativas atribuídas aos municípios. Se de um lado a existência da legislação da escala local é cogente, por outro lado, pouco efeito produz, se não houver compreensão da política inclusiva que caracteriza o $\mathrm{MEI}$, ou, dito de outra forma: não se trata de um canal de arrecadação fiscal do município, ao contrário, é uma política que exige investimento, o que deve ser compreendido pelos governos. Apesar do forte potencial da legislação na escala local, esta se torna ineficaz se não houver equipe técnica, recursos e vontade política, com articulação de arranjos voltados ao MEI.

Como se percebe, a importância das iniciativas legislativas para instituir a política pública do MEI perpassa por diferentes escalas, cuja atuação torna-se necessária, para garantir o atendimento do objetivo estabelecido pela Constituinte de 1988 (BRASIL, 1988), cada uma na medida de suas competências administrativas e legislativas. A legislação, na escala local, embora fundamental, deverá estar articulada às demais legislações criadas no âmbito das outras escalas.

\section{Referências}

BRANDÃO, Carlos. O campo da economia política do desenvolvimento: o embate com os "Iocalismos" na literatura e nas políticas públicas contemporâneas. In: Brandão, C. Território e Desenvolvimento: as múltiplas escalas entre o local e o global. Campinas: Unicamp, 2007.

BRASIL. Constituição Federal de 1988. Promulgada em 5 de outubro de 1988. Brasília, 1988

. Lei Complementar no 123, publicada em 14 de dezembro de 2006. Institui o Estatuto Nacional da Microempresa e da Empresa de Pequeno Porte. Brasília, 2006.

. Lei Complementar no 128, publicada em 19 de dezembro de 2008. Altera a Lei Complementar $n^{\circ} 123$, de 14 de dezembro de 2006, altera as Leis $n$ os 8.212 , de 24 de julho de 1991, 8.213, de 24 de julho de 1991, 10.406, de 10 de janeiro de 2002 - Código Civil, 8.029, de 12 de abril de 1990, e dá outras providências, Brasília, 2008.

. Lei no 10.406, de 10 de janeiro de 2002. Institui o Código Civil. Disponível em:

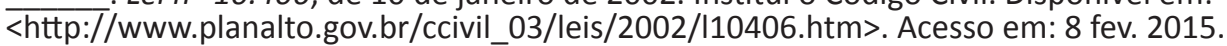

. Lei no 11.110, de 25 de abril de 2005. Institui o Programa de Microcrédito

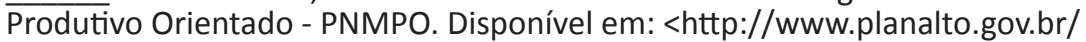
Ccivil_03/_Ato2004-2006/2005/Lei/l11110.htm>. Acesso em: 10 fev. 2015.

. Lei no 12.792, de 28 de março de 2013. Altera a Lei no 10.683, de 28 de maio de 2003, que dispõe sobre a organização da Presidência da República e dos Ministérios, criando a Secretaria da Micro e Pequena Empresa, cargo de Ministro de Estado e cargos em comissão, e a Lei Complementar $n$ o 123, de 14 de dezembro de 2006; e dá outras providências. Disponível em: <http://www.planalto.gov.br/ ccivil_03/_Ato2011-2014/2013/Lei/L12792.htm>. Acesso em: 5 fev. 2015. 
CARGNIN, Antônio Paulo. Escalas de poder e gestão e a implementação de políticas de desenvolvimento regional no estado do Rio Grande do Sul. Revista Política e Planejamento Regional (PPR), Rio de Janeiro, v. 1, n. 1, jan./jun. 2014.

MENDES, Gilmar F.; BRANCO, Paulo Gustavo Gonet; COELHO, Inocêncio Mártires Coelho. Curso de Direito Constitucional. São Paulo: Saraiva, 2007.

MORAIS, Luiz Gonzaga Lima de. TCE e MP alertam prefeitos para aprovarem lei do empreendedor individual. In: Revista da Semana, 15 ago. 2010. Disponível em: <http://www.revistadasemana.com>. Acesso em: 14 abril de 2014.

RIO GRANDE DO SUL. Lei no 13.601, de 1 de janeiro de 2011. Dispõe sobre a estrutura administrativa do poder executivo do estado do Rio Grande do Sul e dá outras providências. Disponível em: <http://www.portaldeacessibilidade.rs.gov.br/ uploads/1295351467Leix13.601xdex01xdexjaneiroxdex2011xNovasxSecretarias.pdf>. Acesso em: 7 jan. 2015.

. Redes de cooperação. Disponível em: <http://www.sesampe.rs.gov.br/redes_ cooperacao.php\#mapa>. Acesso em: 6 jan. 2015.

SEBRAE. Perfil do microempreendedor individual 2012. Série Estudos e Pesquisas.

Disponível em: <http://www.sebrae.com.br/Sebrae/Portal\%20Sebrae/Estudos\%20e\%20 Pesquisas/perfil_MEI_2012.pdf>.Acesso em: 6 jan. 2015.

VAINER, Carlos. As escalas do poder e o poder das escalas: o que pode o poder local? Anais do ENANPUR, 2001. p. 140-151. Disponível em: <www.anpur.org.br/revista/ rbeur/index.php/anais/article/.../2147/2100>. Acesso em: 14 abril de 2014. 